\title{
Erratum to: Intra-annual bison body mass trajectories in a tallgrass prairie
}

\author{
Joseph M. Craine ${ }^{1}$ - E. Gene Towne ${ }^{1,2} \cdot$ Andrew Elmore $^{2}$
}

Published online: 6 June 2015

(C) Mammal Research Institute, Polish Academy of Sciences, Białowieża, Poland 2015

\section{Erratum to: Mamm Res}

\section{DOI 10.1007/s13364-015-0227-z}

The original version of this article unfortunately contains an error in page 2, first line of the second paragraph under the "Field methods" section which reads, "The scale was installed on 28)". It has read, "The scale was installed on DOY 87 (Mar 28)".

The revised paragraph is presented here:

"The scale was installed on DOY 87 (Mar 28), but the RFID reader was not installed until day of year (DOY) 118 (Apr 28). The last weight recorded for this study was on DOY 269 after which animals were isolated from the scale in preparation for the annual round-up. Once weight data collection began, tagged bison calves were yearlings, and the former were 2 years old. Data were downloaded weekly."

The online version of the original article can be found at $10.1007 /$ s13364-015-0227-z.

Joseph M. Craine

josephmcraine@gmail.com

Jonah Ventures, Manhattan, KS 66502, USA

2 Appalachian Laboratory, University of Maryland Center for Environmental Science, Frostburg, MD 21532, USA 